\title{
STOCHASTIC SIMULATION OF PITTING DEGRADATION OF MULTI-BARRIER WASTE CONTAINER IN THE POTENTIAL REPOSITORY AT YUCCA MOUNTAIN
}

\section{J.H. Lee, J.E. Atkins, and R.W. Andrews}

NTERA, Inc./CRWMS M\&O

101 convention Center Drive, Suite P-110, Las Vegas, Nevada, 89109, USA

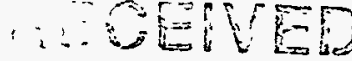 \\ MR: 1900}

ABSTRACT

A detailed stochastic waste package degradation simulation model was developed incorporating the humid-air and aqueous general and pitting corrosion models for the carbon steel corrosion-allowance outer barrier and aqueous pitting corrosion model for the Alloy 825 corrosion-resistant inner barrier. The uncertainties in the individual corrosion models were also incorporated to capture the variability in the corrosion degradation among waste packages and among pits in the same waste package. Within the scope of assumptions employed in the simulations, the corrosion modes considered, and the near-field conditions from the drift-scale thermohydrologic model, the results of the waste package performance analyses show that the current waste package design appears to meet the 'controlled design assumption' requirement of waste package performance, which is currently defined as having less than $1 \%$ of waste packages breached at 1,000 years [1]. It was shown that, except for the waste packages that fail early, pitting corrosion of the corrosion-resistant inner barrier has a greater control on the failure of waste packages and their subsequent degradation than the outer barrier. Further improvement and substantiation of the inner barrier pitting model (currently based on an elicitation) is necessary in future waste package performance simulation model.

\section{INTRODUCTION}

The current design concept for the potential repository at Yucca Mountain employs a robust waste package design and other defense-in-depth engineered barrier system (EBS) components. A multi-barrier waste container is the primary EBS component and one of the major components in the current waste isolation and containment strategy. A thick layer (about $100 \mathrm{~mm}$ ) of carbon steel corrosion-allowance material (CAM) has been proposed as the outer containment barrier, and a thin layer (about $20 \mathrm{~mm}$ ) of Alloy 825 corrosion-resistant material (CRM) as the inner containment barrier [1].

Given that the waste package must "fail" (i.e., be breached to an extent that the mobile water present in the near field environment can ingress into the waste package and any dissolved radionuclides can be transported out of the package) before any dissolution of the waste form can occur, it is important to be able to predict waste package degradation.

"Failure" of waste package is defined as having at least one pit penetration through the waste container [1]. The degradation rate of the waste container is dependent on (1) the waste container design (in particular the material(s) used in the waste container fabrication and the thickness of these material(s)), (2) the near-field thermo-chemical-hydrologic regime (driven by the repository design such as the thermal load, the presence of backfill, etc.) in the drifts adjacent to the waste container surface (in particular the temperature, relative humidity, and chemical and redox conditions), and (3) the degradation characteristics of the waste container materials (including the criteria for corrosion initiation and the rate of corrosion as a function 
of the near field thermo-chemical-hydrologic environment). Information from each of these topics is required as input to the waste container degradation model to predict the rate of "failure" of the waste packages. This paper discusses the detailed stochastic waste container degradation simulation model which was developed recently for the total system performance assessment-1995 (TSPA-1995) for the potential repository [2].

\section{CORROSION MODELS FOR THE BARRIER MATERIALS}

The stochastic waste container degradation simulation model incorporates the following five individual corrosion models: (1) humid-air general corrosion model (including uncertainty) for the CAM outer barrier; (2) stochastic humid-air pitting corrosion model for the CAM outer barrier; (3) aqueous general corrosion model (including uncertainty) for the CAM outer barrier; (4) stochastic aqueous pitting corrosion model for the CAM outer barrier; and (5) aqueous pitting corrosion model (including pit growth rate distribution) for the CRM inner barrier. Details of the humid-air and aqueous general and pitting corrosion models for CAM are given by Lee, et al. [3]. The uncertainties of the individual corrosion models are treated stochastically in the waste container simulation model as discussed later.

A pitting corrosion model for the Alloy $825 \mathrm{CRM}$ inner barrier, which was developed from an elicitation discussed in the previous TSPA [4], is employed in the stochastic waste container degradation simulation. The elicitation provides a range of "constant" (timeindependent) pit growth rates in aqueous conditions at 70 and $100^{\circ} \mathrm{C}$. In the elicitation, the pit growth rate ranges are presented as the median, 95th percentile and 5th percentile growth rates. Since pits grow at a decreasing rate with time, the "constant" pit growth rates given in the elicitation are conservative. An improved pitting model is expected when more siterelevant pitting corrosion data become available. For the pit growth rate ranges at other temperatures, these values were extrapolated as a function of temperature in an Arrheniustype functional form. The resulting functional form for the median pit growth rate is given as follows:

$$
\ln R_{p}=50.373-\frac{19655.85}{T}
$$

where $R_{p}$ is the constant pit growth rate $(\mathrm{mm} / \mathrm{yr})$, and $T$ is temperature $(K)$. The median pit growth rate as a function of temperature is shown in Fig. 1 along with the 95th and 5th percentile growth rates. The pit growth rate decreases exponentially with decreasing temperature, and the rate at room temperature is about 6 orders of magnitude less than the rate at $100^{\circ} \mathrm{C}(373 \mathrm{~K})$. In the stochastic simulation model, pit growth rates for the Alloy 825 inner barrier are sampled randomly, based on the 95 th and 5 th percentile pit growth rate ranges.

\section{STOCHASTIC WASTE PACKAGE DEGRADATION SIMULATION MODEL}

An overview of the stochastic waste package degradation simulation model is shown in Fig. 2. The humid-air and aqueous general and pitting corrosion models (with uncertainties) for the carbon steel outer barrier, and the aqueous pitting corrosion model (with uncertainties) for the Alloy 825 inner barrier are incorporated into the stochastic waste package degradation simulation module. The drift-scale temperature and humidity profiles at the waste container 


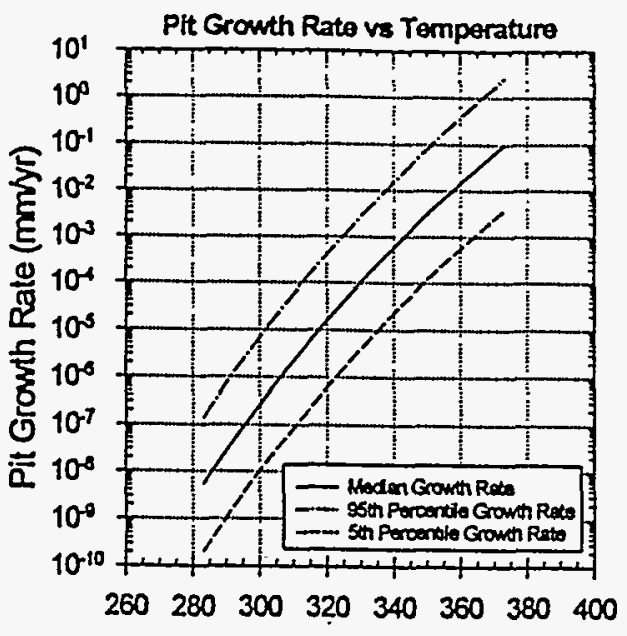

Exposure Temperature $(K)$

surface are fed into the waste package degradation simulation module as a lookup table. The waste package degradation simulation module calls on appropriate corrosion model(s) depending on the near-field environment and the waste container degradation at a given time step. The simulation module provides as output the "failure" time for each waste package, which corresponds to the time for the initiation of waste form alteration (or radionuclide mobilization) inside the waste package. The simulation module also provides the pitting history of a "failed" waste container in terms of the number of pit penetrations as a function of time. A total number of pit penetrations at a given time gives an area on the waste container that is available for transport of mobilized radionuclides through the waste container. The waste package "failure" time and subsequent pitting history of the container are incorporated into the EBS transport model.

The algorithm for the waste package degradation simulations is described in the flow chart shown in Fig. 3. In the simulations, the time steps are discretized such that within any time step, both the relative humidity and the temperature are relatively constant (e.g., within $2 \%$ difference in a given time step). For each simulated waste package, random values are selected to represent the mean values on that particular waste container of each of the parameters in the corrosion models. This selection process is represented by the second box in the flow chart. Based on the mean values already selected for each waste container, random values were sampled for each pit to represent the parameters in the corrosion models. This is

Stochastlc Wasta Package Degradation Simulation Model

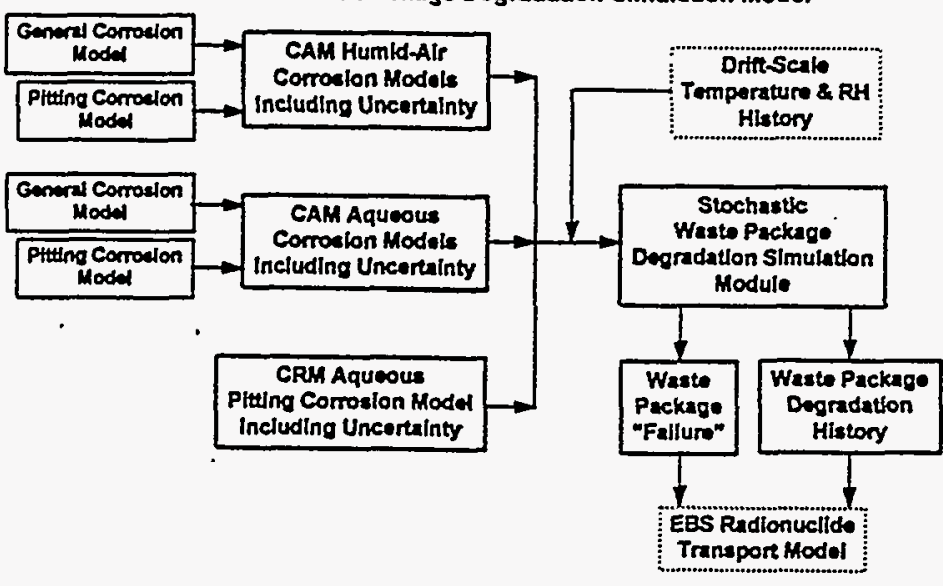

Fig. 2 An overview of the stochastic waste package degradation simulation model. represented by the third box in the flow chart.

Once the parameter values for the corresponding corrosion model are known for a given pit, the depth of that pit is tracked through each time step. Within each time step, the average relative humidity and temperature are calculated. These are used to determine whether humid-air or aqueous corrosion is occurring, and at what rate corrosion is occurring. Based on this information, the model calculates how much corrosion occurs during . that time step, and checks if the pit 


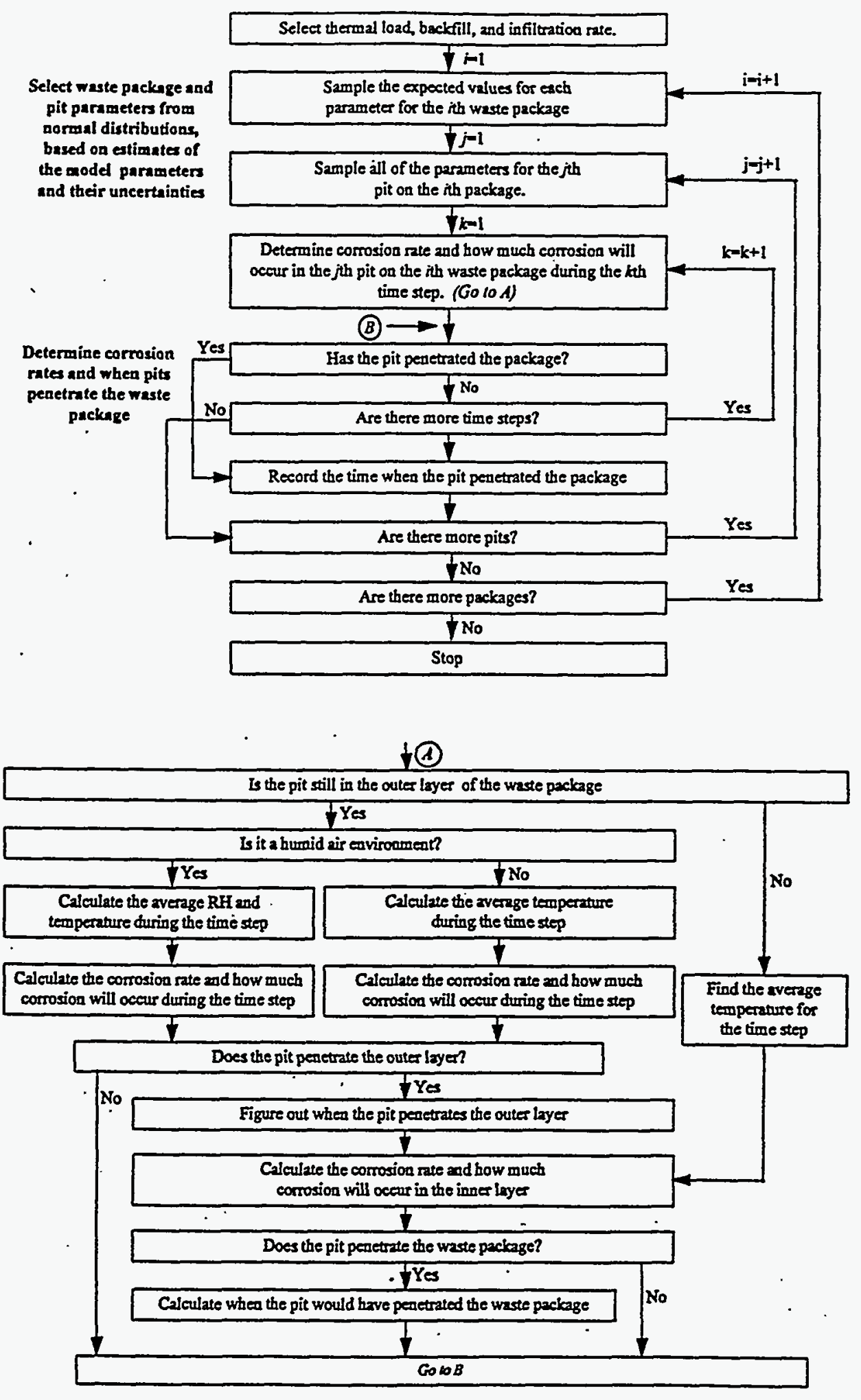

Fig. 3 Flowchart of the stochastic waste package degradation simulation model.

penetrates the waste container. If the pit penetrates the waste container during that time step, then the time when the pit penetrates the waste container is also calculated. This is illustrated in the fourth through seventh boxes of the flow chart. 
Major assumptions made in the stochastic waste package degradation simulation are discussed in the following section. Reference(s) for the basis of the assumptions are given if available.

(1) Humid-air general and pitting corrosion of the carbon steel outer barrier is assumed to initiate when the waste container surface temperature is below $100^{\circ} \mathrm{C}$ and the relative humidity $(\mathrm{RH})$ reaches a threshold value which is uniformly distributed between 65 and $75 \%[5,6]$. Aqueous general and pitting corrosion of the outer barrier is assumed to initiate at a threshold $\mathrm{RH}$ which is uniformly distributed between 85 and $95 \% \mathrm{RH}$ [7].

(2) Complete and positive correlation of the humid-air corrosion initiation threshold and the transition threshold from humid-air corrosion to aqueous corrosion is assumed. That is, if humid-air corrosion initiates at $65 \% \mathrm{RH}$, then aqueous corrosion initiates at $85 \%$ RH.

(3) The Alloy 825 corrosion resistant inner barrier material is assumed to be subjected to aqueous pitting corrosion only (not to general corrosion) [8].

(4) When pits reach the inner barrier through the outer barrier, aqueous conditions are assumed. This is based on the observations that the capillary condensation of moisture by gel-like porous corrosion products of the outer barrier covering the inner barrier surface [5] and the hygroscopic nature of many corrosion products [7,9] would provide an aqueous corrosion condition at the surface of the inner barrier.

(5) In the post-closure repository, about 10,000 waste packages will be spread over the repository area, and a local corrosion environment in one part of the repository may be different from that in another part. This variability of the local corrosion environment is referred to here as waste package to waste package variability. Also, since a waste container has a relatively large surface area (about $37 \mathrm{~m}^{2}$ ), the corrosion rate on one part of the waste container may be different from that on another part of the waste container. This variability in the corrosion rate on a waste container is referred to here as pit to pit variability. The variability among waste packages and the variability among pits are accounted for by equally splitting the uncertainties in the corrosion models into the two variabilities. The variability in the pitting factor for the carbon steel outer barrier is used entirely for pit to pit variability.

(6) The carbon steel outer barrier has a pit density of $10 \mathrm{pits} / \mathrm{cm}^{2}[10-12]$, and the same pit density is also assumed for the inner barrier. The pits are assumed to form uniformly over the entire waste package surface, and a "constant" pit radius of 0.56 $\mathrm{mm}$ is assumed for all the pits.

(7) All the pits that can form on a waste container start to grow at the same time when the waste container surface reaches the threshold conditions given in Assumption (1), i.e. pit initiation is not explicitly considered.

\section{RESULTS AND DISCUSSION}

The temperature and humidity profiles at the waste container were provided from a driftscale thermohydrologic model of the near-field environment, which was based on a realistic geometric configuration. Detailed descriptions of the thermohydrologic model and the 


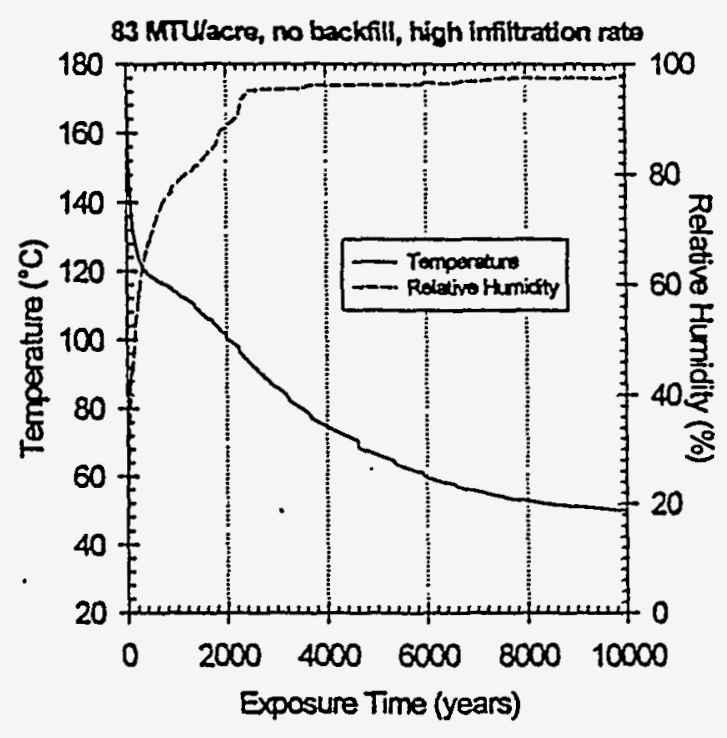

Fig. 4 Temperature and $\mathrm{RH}$ profiles at the waste container surface for the case of $83 \mathrm{MTU} / \mathrm{acre}$, high infiltration rate, and without backfill. calculation results are given in the recent M\&O reports $[2,13]$. Shown in Fig. 4 are the calculated results for the temperature and $\mathrm{RH}$ profiles with time at the waste container surface for the case of $83 \mathrm{MTU} / \mathrm{acre}$, high infiltration rate $(0.3 \mathrm{~mm} / \mathrm{yr})$, and without backfill. The container surface temperature reaches the maximum at about $170^{\circ} \mathrm{C}$ between 10 and 20 years, then decreases to $100^{\circ} \mathrm{C}$ at about 2,000 years, and continues to decrease steadily towards the ambient temperature. The RH at the waste container surface remains below $70 \%$ until about 400 years It reaches about $80 \%$ at 1,000 years, about $90 \%$ at 2,000 years and about $98 \%$ at 10,000 years. These temperature and $\mathrm{RH}$ profiles were incorporated into the stochastic waste package degradation simulation model.

A set of simulations for the above case was performed assuming that corrosion of the carbon steel outer barrier initiates when the temperature at the waste container

surface becomes less than $100^{\circ} \mathrm{C}$ and the relative humidity is above the threshold value defined in Assumption (1). The simulation results discussed below are for a total of 400 waste containers with 250,000 pits per waste container. In the simulation, all the waste containers is assumed to have the same temperature and relative humidity profiles shown in Fig. 4; however, the variability in the corrosion rates due to the potential variations in the local near-field environment (i.e., including the effects of the temperature and relative humidity variations) are captured as discussed in Assumption (5). The use of a reduced number of waste packages and pits are due primarily to the constraints in computing resources. It was demonstrated that similar simulation results are obtained with a higher number of waste containers and pits [2].

The simulation results are shown in Figs. 5-(A) and (B). As previously indicated, at about 2,000 years the waste container temperature decreases to $100^{\circ} \mathrm{C}$, and $\mathrm{RH}$ approaches about $90 \%$. Thus, most of the waste packages in the repository are exposed to an aqueous corrosion condition. The effects of this aqueous corrosion environment at elevated temperatures are illustrated in Fig. 5-(A) which presents the "failure" (i.e., at least one pit penetration) history (or "empirical" cumulative density function(CDF)) for 400 waste containers. Also shown in the figure is the empirical CDF of waste packages with the outer barrier failure. Points in the two CDFs do not necessarily correspond each other (for example, the fifth waste package with the outer barrier failure is not necessarily the fifth waste package with the inner barrier failure). Waste packages start to fail at about 2,200 years, and the number of failed waste packages increases rapidly before beginning to flatten out at about 6,000 years. As shown in the figure, once they begin to fail, all the outer barriers fails in a short period, while the inner barrier failures spread out with time (particularly in later times), and this is due mostly to the exponentially decreasing pit growth rate with temperature (Fig. 1). 
This result is expected from the temperature and humidity profiles at the waste container surface (Fig. 4). After corrosion initiates at about 2,000 years, the waste container temperature steadily decreases from 100 to $70^{\circ} \mathrm{C}$ at about 4,500 years, and $\mathrm{RH}$ is between 90 and $95 \%$ during this time period. This indicates that the carbon steel outer barrier of most waste packages undergo aqueous corrosion at high corrosion rates. Additionally, at these temperature conditions, the "constant" (time-independent) pit growth rate for the inner barrier (Fig. 1) is also high. It is also shown in the figure that about $6 \%$ of the waste packages do not have a first pit penetration by 100,000 years.

Representative pitting histories for 25 waste packages, randomly selected from the waste packages that fail before 100,000 years, are shown in Fig. 5-(B). The waste package with the 'highest pit penetrations' has about $4 \%$ of the total of 250,000 pits penetrated at 10,000 years, and then the number of pit penetrations increase steadily. This is caused mainly by a very . low pit growth rate for the inner barrier beyond 10,000 years (i.e., the waste container temperature decreases to about $50^{\circ} \mathrm{C}$ at 10,000 years). Other waste packages follow similar pitting histories.

83 MTU/acre; No Backfill; High Infiltration

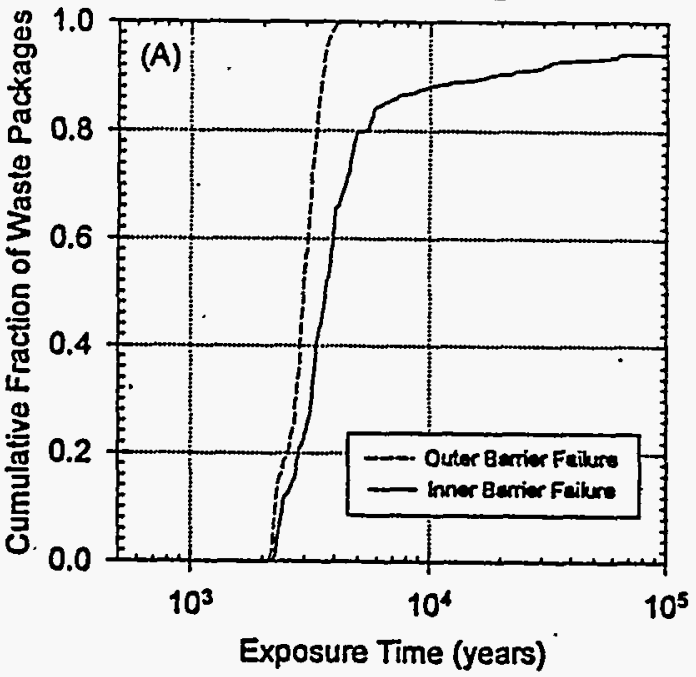

83 MTU/acre; No Backfill; High Infittration

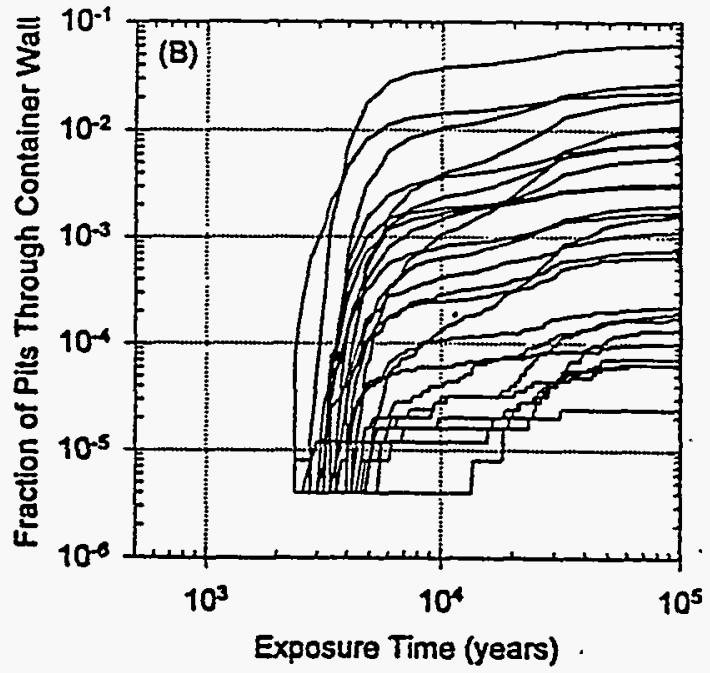

Fig. 5 Waste package degradation simulation results for the case of 83 MTU/acre, high infiltration rate, and without backfill: (A) waste package failure history; and (B) representative pitting histories for 25 waste packages.

\section{SUMMARY AND CONCLUSIONS}

A detailed stochastic waste package degradation simulation model has been developed, and the stochastic simulation model incorporates the following five individual corrosion models: 1) humid-air general corrosion model for the carbon steel corrosion-allowance outer barrier; 2) stochastic humid-air pitting corrosion model for the carbon steel outer barrier; 3) aqueous general corrosion model for the carbon steel outer barrier; 4) stochastic aqueous pitting corrosion model for the carbon steel outer barrier; and 5) aqueous pitting corrosion model for the Alloy 825 corrosion-resistant inner barrier. The uncertainties in the individual corrosion models were incorporated to capture the variability in the corrosion degradation among waste packages and among pits in the same waste package. 
Within the scope of assumptions employed in the simulations, the corrosion modes considered, and the near-field conditions from the drift-scale thermal-hydrologic model, the results of the waste package performance analyses show that the current waste package design appears to meet the 'controlled design assumption' requirement of waste package performance, which is currently defined as having less than $1 \%$ of waste packages breached at 1,000 years [1]. Breach (or "failure") of waste package is defined as having at least one pit penetration through the container.

It has been shown in the simulation result analyses that, except for the waste packages that fail early, pitting corrosion of the corrosion-resistant inner.barrier has a greater control on the failure of waste packages and their subsequent degradation than the outer barrier. The current aqueous pitting corrosion model for the inner barrier is based on an expert elicitation and is expressed as a distribution of "constant" (time-independent) pit growth rate as a function of exposure temperature only. The inner barrier pitting corrosion model should be improved and substantiated in future waste package performance analyses. Other important parameters that need to be included in the inner barrier pitting corrosion model would be the effects of near-field chemical environments and exposure time. It has been reported that localized corrosion such as pitting and stress corrosion cracking are interrelated because the sites of localized corrosion attack become the sources of initiation of stress corrosion cracking $[14,15]$. Thus, synergistic effects of pitting and other localized corrosion combined with stress corrosion cracking need to be included in future waste package performance analyses. Additionally, the effects of microbiologically influenced corrosion on waste package performance should also be included.

\section{ACKNOWLEDGEMENTS}

This work was funded by the US DOE Yucca Mountain Site Characterization Office under Contract \#DE-AC01-91RW00134 to TRW Environmental Safety systems, Inc. The authors gratefully acknowledge S. Lingineni for providing the temperature and relative humidity profiles used in the simulations.

\section{REFERENCES}

1. CRWMS M\&O, Controlled Design Assumption Decument, B00000000-01717-460000032, Rev. 01, April 28, 1995.

2. CRWMS M\&O, Total System Performance Assessment-1995: An Evaluation of the Potential Yucca Mountain Repository, B00000000-01717-2200-00136, Rev. 01, Nov. 1995.

3. J.H. Lee, J.E. Atkins, and R.W. Andrews, this volume.

4. R.W. Andrews, T.F. Dale, and J.A. McNeish, Total System Performance Assessment1993: An Evaluation of the Potential Yucca Mountain Repository, CRWMS M\&O Report, B00000000-01717-2200-00099, Rev. 01, Las Vegas, NV, March 1995.

5. W.H. Vernon, Trans. Electrochem. Soc., 64, p. 31 (1933).

6. P.B. Phipps, and D.W. Rice, in Corrosion Chemistry, edited by G.R. Brubaker, and P.B. Phipps, ACS Symp. Ser. 89, Am. Chem. Soc., 1979, p. 235.

7. F.H. Haynie, J.W. Spence, and J.B. Upham, in Atmospheric Eactors Affecting the Corrosion of Engineering Metals, ASTM STP 646, edited by S.K. Coburn, ASTM, 1978, p. 30 . 
8. J.A. Beavers and C.L. Durr, Immersion Studies on Candidate Container Alloys for the Tuff Repository, NUREG/CR-5598, Cortest Columbus Technologies, Columbus, OH, 1991.

9. D. Fyfe, in Corrosion: Yol 1-Metal/Environment Reactions, 3rd Ed., edited by L.L.

Shreir, R.A. Jarman, and G.T. Burstein, Butterworth-Heinemann, p. 2:31 (1994).

10. G.P. Marsh, and K.J. Taylor, Corrosion Science, 28, p. 289 (1988).

11. G.P. Marsh, K.J. Taylor, and Z. Sooi, SKB Technical Report 88-09 (Feb. 1988).

12. J.E. Strutt, J.R. Nichols, and B. Barbier, Corrosion Science, 25, p. 305 (1985).

13. S. Lingineni, M. Reeves, and S. Mishra, Hydrothermal Analyses at the Waste Package/Drift Scale. A Benchmarking Study with FEHM and TOUGH2, CRWMS M\&O Report, BBA000000-01717-0200-00001, Las Vegas, NV, 1994.

14. J.C. Farmer, R.A. Van Konynenburg, R.D. McCright, and D.B. Bullen, Survey of Degradation Modes of Candidate Materials for High-Level Radioactive-Waste Disposal Containers. Volume 3: Localized Corrosion and Stress Corrosion Cracking of Austenitic Alloys, UCID-21362 Vol. 3, Lawrence Livermore National Laboratory; Livermore, CA, 1988.

15. J.C. Farmer, and R.D. McCright, in Scientific Basis for Nuclear Waste Management XII, edited by W. Lutze and R.C. Ewing, Mater. Res. Soc. Proc. Vol. 127, Pittsburg, PA, 1989, p. 359.

\section{DISCLAIMER}

This report was prepared as an account of work sponsored by an agency of the United States Government. Neither the United States Government nor any agency thereof, nor any of their employees, makes any warranty, express or implied, or assumes any legal liability or responsibility for the accuracy, completeness, or usefulness of any information, apparatus, product, or process disclosed, or represents that its use would not infringe privately owned rights. Reference herein to any specific commercial product, process, or service by trade name, trademark, manufacturer, or otherwise does not necessarily constitute or imply its endorsement, recommendation, or favoring by the United States Government or any agency thereof. The views and opinions of authors expressed herein do not necessarily state or reflect those of the United States Government or any agency thereof. 